\title{
BUILDING PERFORMANCE AND OCCUPANCY EVALUATION FOR PUBLIC BUILDING STOCK MANAGEMENT: A STATE OF THE ART
}

\author{
GIUSEPPE MARTINO DI GIUDA, LAURA PELLEGRINI, and ELENA SEGHEZZI \\ ABC Department, Politecnico di Milano, Milano, Italy
}

\begin{abstract}
The research aims at providing a state of the art regarding the use of Post-occupancy evaluations (POEs) to optimize the facility management phase of large building stocks. Building occupancy evaluations are common topics in the field of building energy performance studies, with recent attention on the impacts of user actions and movements on building performances. Most part of the research implied the use of sensors to monitor these aspects, providing huge amounts of data regarding large building stocks. The research provides a literature review about: methods, tools, and existing studies regarding the use of sensors to monitor occupancy values at room level and users' flows; applications of machine learning (ML) techniques to analyze large amounts of sensor data and provide valuable predictive information on facility management; existing types of ML techniques and related feasibility for the presented purposes. In addition, the paper investigates the integration in a BIM approach to visualize occupancy levels and predictive information in the Information Model. Potential applications to facilitate the optimization of cleaning activities and reorganization of spaces in large building stocks are also explored, investigating the setting of a decision support system for facility managers to handle building management and cleaning activities using predictive information.
\end{abstract}

Keywords: Public building portfolio, Post-occupancy evaluation, Machine learning techniques, Occupancy levels, BIM, Building management, Decision support system.

\section{INTRODUCTION}

Post-occupancy evaluations (POEs) in the Architecture, Engineering, Construction and Operations (AECO) sector, also called "building-in-use-studies" (Preiser 1995), have been defined as "the most cost-effective way of improving service to future clients" (Royal Institute of British Architects (RIBA) 1965).

Historically, the performance of buildings had been assessed informally and lessons learned had been applied in the next construction cycle of a similar structure. Nowadays, a multitude of building specialists takes part in the building life cycle, each one with specific targets and requirements (Preiser 1995). At the same time, clients are placing ever-increasing demands on buildings (Preiser 1995), which are, in many cases, different from user needs (Zimmerman and Martin 2001). The lack of a common understanding between owners and specialists' and users' requirements leads to the need to analyze existing buildings and use the feedback to optimize them and future similar buildings. In addition, the actual use of spaces and resources and users' behavior have strong impacts on the consumptions and functionality of an existing building (Bento Pereira et al. 2016). Therefore, the application of POEs should be a standard practice 
during this phase to assess the building performances. Nevertheless, as of now, most of it is still academic research or case studies. In most cases, the building is still a prototype of itself with regard to the actual use (Zimmerman and Martin 2001).

This research aims at providing state-of-the-art about building occupancy detection and related use of sensors, fields, and tools for the application of POEs and the possible application of machine learning (ML) techniques. This work would also investigate the integration in a BIM approach and the definition of a decision support system (DSS) for facility managers to optimize spaces and resources for the operational phase of buildings.

\section{METHODOLOGY}

The method adopted involved the use of some online search tools: Web of Science, Google Scholar, and Scopus were used for a first research about POEs, sensors, and ML. From the first group of publications, it was possible to define a set of common keywords, which were used to filter the results of the research for other publications. The articles collected were then sorted using the free reference management software Mendeley, provided with all the useful metadata, checked for duplicates, and analyzed in order to define the main topics that each one was referring to. Finally, regarding each of the topics investigated in this work, only the most relevant publications were chosen as a base for the literature review.

\section{OCCUPANCY DETECTION AND MACHINE LEARNING TECHNIQUES}

\subsection{The Use of Sensors to Monitor Occupancy}

To date, the use of sensors as a part of POEs to monitor existing buildings have been mostly focused on analyzing energy performances and consumptions and indoor environmental quality (IEQ) (Costa et al. 2015, Delzendeh et al. 2017, Yan et al. 2017, Saralegui et al. 2018, Demian et al. 2018, Rogage et al. 2019, Wang et al. 2019a, Wang et al. 2019b). Recently, applications of sensors to detect occupancy flows have been explored, mainly referring to building energy consumption analyses and predictive models (Diraco et al. 2015, Yan et al. 2017, Saralegui et al. 2018, Rouleau et al. 2019, Wang et al. 2019b), as presented in Table 1.

The best accuracy was obtained by camera-based sensors and PIR sensors, followed by $\mathrm{CO}_{2}$ sensors, as shown in Table 1. While PIR sensors showed issues in detecting stationary occupancy, camera-based sensors were affected by privacy issues because of the recording of images and the Hawthorne Effect, that is an alteration of behavior when aware of being observed, that can affect the reliability of collected data (Yan et al. 2017).

One of the main strategies implies the combination of more sensors to detect occupancy (Wang et al. 2019b). The first advantage is the possibility of installing only a few new sensors and reuse some of existing PIR sensors linked to security detection systems or Wi-Fi connections. This solution also allows using cheaper types of sensors, sacrificing some accuracy, but at the same time facilitating a large implementation of sensor systems and the spread of POE applications due to the decreasing costs. 
Table 1. Sensor systems and related features to monitor occupancy.

\begin{tabular}{|c|c|c|c|c|}
\hline Sensor type & Main aspects & Pros & Cons & References \\
\hline $\begin{array}{l}\text { Camera- } \\
\text { based } \\
\text { sensors }\end{array}$ & $\begin{array}{l}\text { - Average accuracy of } \\
97 \%\end{array}$ & $\begin{array}{l}\text { - High accuracy } \\
\text { - May serve as } \\
\text { security, safety } \\
\text { and recognition } \\
\text { system }\end{array}$ & $\begin{array}{l}\text { Users' presence/ } \\
\text { absence detection only } \\
\text { within the field-of-view } \\
\text { - Privacy issues for } \\
\text { recording images } \\
\text { - Hawthorne effect }\end{array}$ & $\begin{array}{l}\text { (Yan et al. } \\
\text { 2017, Yang et } \\
\text { al. 2018) }\end{array}$ \\
\hline $\begin{array}{l}\mathrm{CO}_{2} \\
\text { concentration } \\
\text { change } \\
\text { sensors }\end{array}$ & $\begin{array}{l}\text { - Average accuracy of } \\
94 \%\end{array}$ & $\begin{array}{l}\text { - Often used in } \\
\text { buildings } \\
\text { - No privacy } \\
\text { issues }\end{array}$ & $\begin{array}{l}\text { - Less reliable than other } \\
\text { type of sensors }\end{array}$ & $\begin{array}{l}\text { (Yan et al. } \\
\text { 2017, Yang et } \\
\text { al. 2018) }\end{array}$ \\
\hline $\begin{array}{l}\text { Visual light } \\
\text { and infrared } \\
\text { (PIR) } \\
\text { technologies }\end{array}$ & $\begin{array}{l}\text { - High accuracy of } 97 \% \\
\text { for unoccupied and } \\
\text { occupied scenarios } \\
\text { Decreased accuracy of } \\
\text { 93\% for stationary and } \\
\text { moving user detection }\end{array}$ & $\begin{array}{l}\text { - High accuracy } \\
\text { - No privacy } \\
\text { issues }\end{array}$ & $\begin{array}{l}\text { Issues in detecting } \\
\text { stationary occupants } \\
\text { - Users' presence/ } \\
\text { absence detection only } \\
\text { within the field-of-view }\end{array}$ & $\begin{array}{l}\text { (Saralegui et } \\
\text { al. } 2018 \text {, } \\
\text { Wang et al. } \\
\text { 2019b) }\end{array}$ \\
\hline $\begin{array}{l}\text { Radio } \\
\text { frequency } \\
\text { identification } \\
\text { (RFID) } \\
\text { sensors }\end{array}$ & $\begin{array}{l}\text { - Accuracy of } 88 \% \text { for } \\
\text { stationary user detection } \\
\text { Decreased accuracy of } \\
65 \% \text { for moving } \\
\text { occupants' detection }\end{array}$ & $\begin{array}{l}\text { - } \quad \text { No privacy } \\
\text { issues } \\
\text { - Widespread } \\
\text { sensors } \\
\text { - Serve as access- } \\
\text { control system }\end{array}$ & $\begin{array}{l}\text { Low accuracy } \\
\text { compared with other } \\
\text { sensor systems }\end{array}$ & $\begin{array}{l}\text { (Li et al. 2012, } \\
\text { Demian et al. } \\
\text { 2018, Wang et } \\
\text { al. 2019b) }\end{array}$ \\
\hline $\begin{array}{l}\text { Wi-Fi } \\
\text { connections }\end{array}$ & $\begin{array}{l}\text { - Average accuracy of } \\
80 \%\end{array}$ & $\begin{array}{l}\text { - Already available } \\
\text { in buildings }\end{array}$ & $\begin{array}{l}\text { Privacy issues to } \\
\text { visualize and analyze } \\
\text { users' connections }\end{array}$ & $\begin{array}{l}\text { (Wang and } \\
\text { Shao 2017, } \\
\text { Rogage et al. } \\
\text { 2019) }\end{array}$ \\
\hline
\end{tabular}

\subsection{Machine Learning Techniques Applied to POEs}

Predictive models based on machine learning (ML) techniques are common in the field of building energy performances (Fan et al. 2019), to find correlations between inputs and outputs based on actual operation data of a building. They can analyze and describe more complicated and nonlinear relationships among data, thus, obtaining more accurate predictions, thanks to the ML algorithms (Fan et al. 2019). The initial process of constructing valuable features as model inputs, namely the feature engineering, can also be optimized by means of ML techniques (Yu et al. 2016, Amasyali and El-Gohary 2018, Fan et al. 2019), leading to evident improvement in building energy predictions (Fan et al. 2019). ML techniques applied to feature engineering allows the multiple transformations of the original data before deriving the outputs. As a result, the features obtained could preserve useful information of the original data ensuring a more accurate prediction of the model (Fan et al. 2019).

Table 2 provides some studies about ML and DL (deep learning) algorithms applied to POEs. Existing studies highlight the importance of feature engineering to optimize predictions, as well as the need to apply more than one model to compare results and define the model that best fits the purposes of POEs. SVM and hybrid models achieved the best results in terms of accuracy and reliability. 
Table 2. Existing ML and DL techniques applied to POEs and related features; only the most significant references have been reported for each analysis.

\begin{tabular}{|c|c|c|}
\hline Reference & ML and DL techniques analyzed & Findings \\
\hline $\begin{array}{l}\text { (Fan et al. } \\
\text { 2019) }\end{array}$ & $\begin{array}{l}\text { Fully-connected autoencoders (AEs), } \\
\text { Convolutional autoencoders (CAEs), } \\
\text { Generative adversarial networks } \\
\text { (GANs), Two conventional data-driven } \\
\text { feature engineering methods }\end{array}$ & $\begin{array}{l}\text { The best technique in constructing high-level features was } \\
\text { GANs, which is however difficult to train and can suffer } \\
\text { from problems of non-convergence, followed by the CAEs } \\
\text { and the AEs }\end{array}$ \\
\hline $\begin{array}{l}\text { (Yu et al. } \\
\text { 2016) }\end{array}$ & $\begin{array}{c}\text { Artificial neural network (ANN), } \\
\text { Decision Tree, Multi-class support } \\
\text { vector machine (SVM), Naïve Bayesian }\end{array}$ & $\begin{array}{l}\text { Multi-class SVM provided more accurate forecasting both } \\
\text { for feature selection and prediction }\end{array}$ \\
\hline $\begin{array}{l}\text { (Ahmad et al. } \\
\text { 2014) }\end{array}$ & $\begin{array}{l}\text { Artificial neural network (ANN), } \\
\text { Support vector machine (SVM), Hybrid } \\
\text { models of ANN and SVM }\end{array}$ & $\begin{array}{l}\text { Hybrid models of ANN and SVM presented higher } \\
\text { accuracy for predictive purposes than the original models } \\
\text { ANN and SVM }\end{array}$ \\
\hline \multirow[t]{4}{*}{$\begin{array}{l}\text { (Amasyali } \\
\text { and El- } \\
\text { Gohary 2018) }\end{array}$} & $\begin{array}{l}\text { Gaussian process regression (GPR), } \\
\text { Support vector regression (SVR), } \\
\text { Artificial neural network (ANN), } \\
\text { Linear regression (LR) }\end{array}$ & $\begin{array}{c}\text { The study analyzed real occupant behavior data collected } \\
\text { through a survey, and simulation data referring to weather } \\
\text { conditions. } \\
\text { Weather-related and occupant behavior-related factors' } \\
\text { prediction: }\end{array}$ \\
\hline & & $\begin{array}{l}\text { - } \quad \text { LR model achieved over } 30 \% \mathrm{CV} \\
\text { - } \quad \text { The other models achieved } 20 \% \mathrm{CV}\end{array}$ \\
\hline & & $\begin{array}{l}\text { A third analysis through the four ML models provided the } \\
\text { cooling energy consumptions, applying the two factors: }\end{array}$ \\
\hline & & $\begin{array}{l}\text { - } \quad \text { Predictions were closed to actual values } \\
\text { - } \quad \text { The four model achieved } 19 \% \mathrm{CV}\end{array}$ \\
\hline
\end{tabular}

\section{INTEGRATION IN A BIM APPROACH AND DEFINITION OF A DSS}

\subsection{Integration of POEs in a BIM Approach}

The integration of POEs in a BIM approach enables the connection between POE data and the building model (Costa et al. 2015, Machado et al. 2017, Rogage et al. 2019), with sensors' data and ML-based occupancy predictions assigned to each room of the model (Pin et al. 2018, Rogage et al. 2019). The integration in a BIM approach has the following advantages:

- The model can be used as a single source and storage of data;

- 3D plan views allow the visual representation of the building space, the quick contextualization of POE results and the quick recognition of areas with higher/lower occupancy levels, for instance, using different filling colors (Pin et al. 2018);

- The model enables the visual identification of the spread of similar issues in an area with the identification of major problems that can cause minor related issues, as well as the recognition of seasonal patterns or recurring issues in time series data (Pin et al. 2018);

- Each room can be linked to alerts and warnings according to POEs (Rogage et al. 2019);

- Occupancy levels can be linked to other types of data, such as indoor conditions, space features, expected occupancy, functions, and also survey-based user satisfaction values, allowing to analyze the relationships among all types of data.

The integration in a BIM approach can allow the improvement of visualization, understanding, and sharing of data. 


\subsection{Exploring the Definition of a Decision Support System (DSS) for Facility Management}

Occupancy identifies the actual level of use of each room of a building, and it strongly influences cleanliness and use of spaces, that are related to well-being, satisfaction and productivity of users (Kim and de Dear 2012, Agha-Hossein et al. 2013). Occupancy monitoring and the related optimization of spaces and cleaning activities can lead to higher user satisfaction and productivity at work. Data collected by sensors, analyses performed through ML algorithms, and the integration with a BIM model can be the base for the definition of a decision support system (DSS) for facility managers (FM). The DSS would provide predictions related to occupancy values and need for cleaning activities, as well as optimized space reorganizations to support the decision-making process of facility managers. The implementation of a web-based platform can enable the visualization of the model linked to POE data and predictions with the following benefits: i) supporting the definition of actions for better space management to fit variable occupancy (Pin et al. 2018); ii) enabling a user-friendly consultation of the model and related data by all those involved in the building management process (Rogage et al. 2019); iii) providing online surveys on the web platform: the FM could check if the actions carried out are effective and whether or not users' satisfaction increased (Pin et al. 2018)

The advantages presented above are even larger considering large building stocks. In fact, while single case studies are more in-depth analyses but can barely be applied to other studies because of the peculiarity of the case study itself, large building stock analyses seems to be more reliable and more robust to variable parameters (Rouleau et al. 2019). Referring to large building stocks, use of POEs can lead to large savings due to better management of spaces and resources and to improvement of future designs through data collected from several existing buildings.

\section{CONCLUSIONS AND FURTHER DEVELOPMENTS}

The presented literature review aims to support an informed choice about sensor systems, ML algorithms and approaches to perform Post-occupancy evaluations. A smart strategy is to combine a different kind of sensors, reducing the need for accuracy, and including sensors already existing in buildings, such as Wi-Fi connections and PIR sensors. Referring to ML and DL algorithms, SVM and hybrid models provided the best results both in feature engineering and predicting. The integration in a BIM approach highlighted advantages in the quick visualization of results, issues, and resulting patterns, helping the decision-making process related to the facility management of buildings. The BIM model linked to a web-platform can define a DSS to manage cleaning activities and optimize reorganization of spaces, some of the basic features affecting user satisfaction and productivity at work. In conclusion, the reviewed methods and tools can support further studies to define a complete method to properly collect and analyze data through POEs, providing predictive information for the optimization of Operation and Maintenance in existing building stocks, based on variable occupancy analyses.

\section{References}

Agha-Hossein, M. M., El-Jouzi, S., Elmualim, A. A., Ellis, J., and Williams, M., Post-Occupancy Studies of an Office Environment: Energy Performance and Occupants' Satisfaction, Building and Environment, 69, 121-130, 2013.

Ahmad, A. S., Hassan, M. Y., Abdullah, M. P., Rahman, H. A., Hussin, F., Abdullah, H., and Saidur, R., $A$ Review on Applications of ANN and SVM for Building Electrical Energy Consumption Forecasting, Renewable and Sustainable Energy Reviews, 33, 102-109, 2014.

Amasyali, K., and El-Gohary, N., Predicting Energy Consumption of Office Buildings: A Hybrid Machine Learning-Based Approach, In Advances in Informatics and Computing in Civil and Construction Engineering, 695-700, 2018. 
Bento Pereira, N., Calejo Rodrigues, R., Fernandes Rocha, P., Bento Pereira, N., Calejo Rodrigues, R., and Fernandes Rocha, P., Post-Occupancy Evaluation Data Support for Planning and Management of Building Maintenance Plans, Buildings, 6(4), 45, 2016.

Costa, A. A., Lopes, P. M., Antunes, A., Cabral, I., Grilo, A., and Rodrigues, F. M., 3 I Buildings: Intelligent, Interactive and Immersive Buildings, Procedia Engineering, 123, 7-14, 2015.

Delzendeh, E., Wu, S., Lee, A., and Zhou, Y., The Impact of Occupants' Behaviours on Building Energy Analysis: A Research Review, Renewable and Sustainable Energy Reviews, 80, 1061-1071, 2017.

Demian, P., Liu, Z., and Deng, Z., Integration of Building Information Modelling (BIM) and Sensor Technology: A Review of Current Developments and Future Outlooks, In CSAE, 2018.

Diraco, G., Leone, A., and Siciliano, P., People Occupancy Detection and Profiling With 3D Depth Sensors for Building Energy Management, Energy and Buildings, 92, 246-266, 2015.

Fan, C., Sun, Y., Zhao, Y., Song, M., and Wang, J., Deep Learning-Based Feature Engineering Methods for Improved Building Energy Prediction, Applied Energy, 240, 35-45, 2019.

Kim, J., and de Dear, R., Nonlinear Relationships Between Individual IEQ Factors and Overall Workspace Satisfaction, Building and Environment, 49, 33-40, 2012.

Li, N., Calis, G., and Becerik-Gerber, B., Measuring and Monitoring Occupancy with an RFID Based System for Demand-Driven HVAC Operations, Automation in Construction, 24, 89-99, 2012.

Machado, F. A., Dezotti, C. G., and Ruschel, R. C., The Interface Layer of a BIM-IoT Prototype for Energy Consumption Monitoring, Systems, Controls, Embedded Systems, Energy, and Machines, 9(1), 9-10, 2017.

Pin, C., Medina, C., and McArthur, J. J., Supporting Post-Occupant Evaluation Through Work Order Evaluation and Visualization in FM-BIM, In ISARC 2018 - 35th International Symposium on Automation and Robotics in Construction and International AEC/FM Hackathon: The Future of Building Things, 2018.

Preiser, W. F. E., Post-Occupancy Evaluation: How To Make Buildings Work Better, Facilities, 13(11), $19-28,1995$.

Rogage, K., Clear, A., Alwan, Z., Lawrence, T., and Kelly, G., Assessing Building Performance in Residential Buildings using BIM and Sensor Data, International Journal of Building Pathology and Adaptation, 132829, 2019.

Rouleau, J., Gosselin, L., and Blanchet, P., Robustness of Energy Consumption and Comfort in HighPerformance Residential Building with Respect to Occupant Behavior, Energy, 188, 2019.

Royal Institute of British Architects (RIBA), Handbook of Architectural Practice and Management, RIBA Publications, London, 1965.

Saralegui, U., Anton, M. A., Arbelaitz, O., and Muguerza, J., An IoT Sensor Network to Model Occupancy Profiles for Energy Usage Simulation Tools, In 2018 Global Internet of Things Summit, GIoTS 2018, 2018.

Wang, J., Tse, N. C. F., and Chan, J. Y. C., Wi-Fi Based Occupancy Detection in a Complex Indoor Space Under Discontinuous Wireless Communication: A Robust Filtering Based on Event-Triggered Updating, Building and Environment, 151, 228-239, 2019a.

Wang, W., Hong, T., Xu, N., Xu, X., Chen, J., and Shan, X., Cross-Source Sensing Data Fusion for Building Occupancy Prediction with Adaptive Lasso Feature Filtering, Building and Environment, $162,2019 \mathrm{~b}$.

Wang, Y., and Shao, L., Understanding Occupancy Pattern and Improving Building Energy Efficiency Through Wi-Fi Based Indoor Positioning, Building and Environment, 114, 106-117, 2017.

Yan, D., Hong, T., Dong, B., Mahdavi, A., D’Oca, S., Gaetani, I., and Feng, X., IEA EBC Annex 66: Definition and Simulation of Occupant Behavior in Buildings, Energy and Buildings, 156, 258-270, 2017.

Yang, J., Pantazaras, A., Chaturvedi, K. A., Chandran, A. K., Santamouris, M., Lee, S. E., and Tham, K. W., Comparison of Different Occupancy Counting Methods for Single System-Single Zone Applications, Energy and Buildings, 172, 221-234, 2018.

Yu, J., Kim, M., Bang, H. C., Bae, S. H., and Kim, S. J., IoT as a Applications: Cloud-Based Building Management Systems for The Internet of Things, Multimedia Tools and Applications, 75(22), 1458314596, 2016.

Zimmerman, A., and Martin, M., Post-Occupancy Evaluation: Benefits and Barriers, Building Research and Information, 29(2), 168-174, 2001. 